\title{
POSTER: Caracterização Estatística do Tempo de Decodificação de Ladrilhos de Vídeos $360^{\circ}$
}

\author{
Henrique Domingues Garcia \\ Departamento de Engenharia Elétrica \\ Universidade de Brasília \\ Brasília, Brazil \\ henriquedgarcia@gmail.com
}

\author{
Mylène C.Q. Farias \\ Departamento de Engenharia Elétrica \\ Universidade de Brasília \\ Brasília, Brazil \\ mylene@ene.unb.br
}

\author{
Marcelo M. Carvalho \\ Departamento de Engenharia Elétrica \\ Universidade de Brasília \\ Brasília, Brazil \\ mmcarvalho@ene.unb.br
}

\begin{abstract}
Resumo-A popularização de vídeos $360^{\circ}$ trouxe consigo desafios significativos para sua transmissão eficiente pela Internet via Dynamic Adaptive Streaming over HTTP (DASH) utilizando a técnica de ladrilhamento ("tiling") e segmentação temporal do vídeo em diferentes qualidades. Em particular, as exigências significativas de largura de banda e tempo exíguo para predição do movimento da cabeça do usuário apontam para a necessidade de uma modelagem acurada do tempo de decodificação dos ladrilhos de vídeos $360^{\circ}$. Esta modelagem permite a requisição otimizada de ladrilhos de vídeo, considerando a limitação de largura de banda e espaço de armazenamento no lado cliente da aplicação. Neste sentido, este trabalho apresenta uma caracterização estatística preliminar do tempo de decodificação de segmentos (chunks) de diferentes conteúdos de vídeos $360^{\circ}$, particionados em ladrilhos de diferentes dimensões e codificados com diferentes taxas de bits.
\end{abstract}

Index Terms-Vídeo omnidirecional, Vídeo $360^{\circ}$, streaming de vídeo, HEVC, DASH.

\section{INTRODUÇÃo}

A visualização de vídeos $360^{\circ}$ (i.e., esférico ou omnidirecional) é uma das aplicações mais populares de realidade virtual (VR) dos últimos anos. Sua adoção tem crescido rapidamente com a evolução dos aparelhos de telefonia móvel, a disseminação de dispositivos head-mounted display (HMD) e de câmeras de captura em $360^{\circ}$. De fato, estima-se que as aplicações VR gerem aproximadamente 254 Petabytes de dados por mês em 2022, quase doze vezes mais do que em 2017 [1]. Atualmente, a transmissão de vídeo $360^{\circ}$ pela Internet faz uso da arquitetura tradicional para transmissão de vídeo $2 \mathrm{D}$, ou seja uma aplicação cliente solicita ao servidor segmentos (ou chunks) pré-armazenados do vídeo de uma certa qualidade via Dynamic Adaptive Streaming over HTTP (DASH) [2]. Para a codificação, primeiramente, toda a esfera do vídeo $360^{\circ}$ é projetada em um plano e, em seguida, um codificador de vídeo como HEVC é usado para comprimir o vídeo. Na maioria dos sistemas atuais, toda a esfera é enviada para o cliente. No entanto, o usuário não consegue visualizar todas as direções ao mesmo tempo. Tipicamente, apenas $16,6 \%$ da esfera é visualizada a cada instante no viewport [3]. Consequentemente, uma fração significativa de largura de banda e armazenamento são desperdiçados. Esta situação é ainda agravada pelo fato de que o vídeo $360^{\circ}$ precisa ser codificado em alta resolução para que a cena apresentada no viewport tenha uma qualidade aceitável.
Para atenuar este problema, uma técnica denominada ladrilhamento espacial ("tiling") dos vídeos foi proposta com objetivo de reduzir a largura de banda necessária para esta aplicação. Cada quadro do vídeo é particionado em ladrilhos que são decodificados e reproduzidos de forma independente. Desta forma, o cliente requere apenas os ladrilhos correspondentes a uma região de interesse (ROI - Region of Interest) para compor o viewport. Baseados nesta técnica, diversos trabalhos propuseram técnicas adaptativas transmissão dos ladrilhos referentes ao viewport do HMD [4]. Os segmentos solicitados e recebidos são armazenados no buffer do cliente para decodificação e apresentação.

Infelizmente, os atuais preditores de direção de visualização do usuário apresentam desempenho aceitável (92\%) apenas para janelas curtas de predição (aprox. 1 segundo). Desta forma, o tempo de decodificação dos ladrilhos é um parâmetro fundamental para o projeto de decodificação escalonada nos atuais sistemas de transmissão adaptativa de vídeos $360^{\circ}$ pela Internet [4]. Mais especificamente, o tempo de decodificação dos ladrilhos tem impacto significativo na quantidade e qualidade dos ladrilhos solicitados para uma dada largura de banda. Atualmente, este tempo de decodificação tem sido estimado grosseiramente, sem maior discussão e aprofundamento do seu comportamento estatístico para as diferentes escolhas de dimensionamento de ladrilhos, taxas de codificação e natureza do conteúdo $360^{\circ}$. Neste sentido, nosso trabalho apresenta uma primeira caracterização estatística do tempo de decodificação de segmentos de vídeos $360^{\circ}$ particionados em ladrilhos.

\section{OBjetivos}

Este trabalho tem como objetivo apresentar uma caracterização estatística preliminar do tempo de decodificação de segmentos (chunks) de vídeos $360^{\circ}$ particionados em ladrilhos de diferentes dimensões, codificados com diferentes taxas pelo HEVC e sobre diferentes conteúdos de vídeos $360^{\circ}$.

\section{Materiais e Métodos}

Foram selecionados 12 vídeos $360^{\circ}$, em projeção equirretangular e com duração de 60 segundos. Para garantir a diversidade de conteúdo e, consequentemente, a complexidade de codificação, os vídeos foram selecionados, de acordo com a mediana da sua informação espacial (SI) e informação 
Tabela I

TAXa DE CODIFICAÇÃo MÉdia E SI/TI dos VídeOs SElECIONAdos

\begin{tabular}{|c|c|c|c|}
\hline Taxa (Mbps) - CRF25 & Vídeo & SI & TI \\
\hline 1.380 & om_nom & 103.37 & 1.81 \\
\hline 2.491 & pluto & 24.64 & 1.95 \\
\hline 3.3989 & masquerade_ball & 73.46 & 2.81 \\
\hline 3.867 & super_mario & 117.95 & 1.18 \\
\hline 19.180 & lions & 39.44 & 14.34 \\
\hline 17.016 & elephants & 78.55 & 9.88 \\
\hline 8.068 & ski & 59.82 & 4.27 \\
\hline 12.433 & clans & 30.26 & 14.54 \\
\hline 12.640 & surf & 67.14 & 15.30 \\
\hline 12.945 & manhattan & 29.08 & 14.26 \\
\hline 18.224 & rollercoaster & 72.17 & 23.51 \\
\hline 12.508 & venice & 24.10 & 12.13 \\
\hline & \multicolumn{3}{|}{}
\end{tabular}

temporal (TI). A Tabela I apresenta um resumo dos valores de SI/TI e das taxas de bit médias correspondentes a um valor comum de CRF (Constant Rate Factor) igual a 25 (que reflete a complexidade de codificação) para todos os vídeos considerados. Os vídeos foram codificados utilizando HEVC (i.e., H.265) com resolução 4K, razão 2:1, 30 fps, e 4 valores de CRF: $15,25,35$ e 45 . Além disso, os vídeos foram particionados em 4 padrões de ladrilhos $(1 \times 1,3 \times 2,6 \times 4$, $12 \times 8$ ) e chunks de 1 segundo, totalizando 365.760 chunks.

Foram realizadas três medições do "user time" da decodificação de cada chunk, com uma única thread. "User time" é o tempo gasto em operações fora do kernel, como operações matriciais, por exemplo, sem considerar alocação dinâmica de memória e outras chamadas de sistema. Para decodificação dos vídeos, utilizamos um computador desktop com processador i7-4770 3.4 GHz com 16 GB de RAM, Ubuntu 18.04.2 LTS e FFmpeg 4.1. Embora não seja a plataforma mais comum de visualização de vídeos $360^{\circ}$, esta primeira caracterização visa obter o comportamento estatístico "típico". Medições futuras serão baseadas em plataformas específicas.

\section{RESUltados Preliminares}

A Figura 1 apresenta histogramas dos tempos de decodificação de cada chunk de todos os vídeos considerados, contendo um único ladrilho para cada tipo de particionamento. Para caracterização do tempo de decodificação, avaliamos diversas distribuições de probabilidade, ajustadas aos dados segundo o critério de máxima verossimilhança. $\mathrm{O}$ critério de seleção das distribuições baseou-se na soma de erros quadráticos (Sum of Squared Error - SSE). As distribuições com melhores resultados foram a Gaussiana Inversa (indicada por "invgauss" nos gráficos), $12^{a}$ distribuição de Burr ("bur12”), BirnbaumSaunders ("fatiguelife") e Log-Normal ("lognorm"). O tempo médio de decodificação dos formatos $1 \times 1,3 \times 2,6 \times 4,12 \times 8$ foram $0,843 \mathrm{~s}, 0,137 \mathrm{~s}, 0,032 \mathrm{~s}$ e $0,009 \mathrm{~s}$ respectivamente e a variância foi de $0,432 \mathrm{~s}, 0,090 \mathrm{~s}, 0,025 \mathrm{~s}$ e $0,007 \mathrm{~s}$ respectivamente. Todos os formatos apresentam correlação linear com a taxa de bits de aproximadamente 0,95 .

Observa-se que, para tiles de formato $(1 \times 1$ e $6 \times 4)$, a distribuição Gaussiana Inversa apresenta o melhor ajuste. No entanto, para os ladrilhamentos $(3 \times 2$ e $12 \times 8)$, a
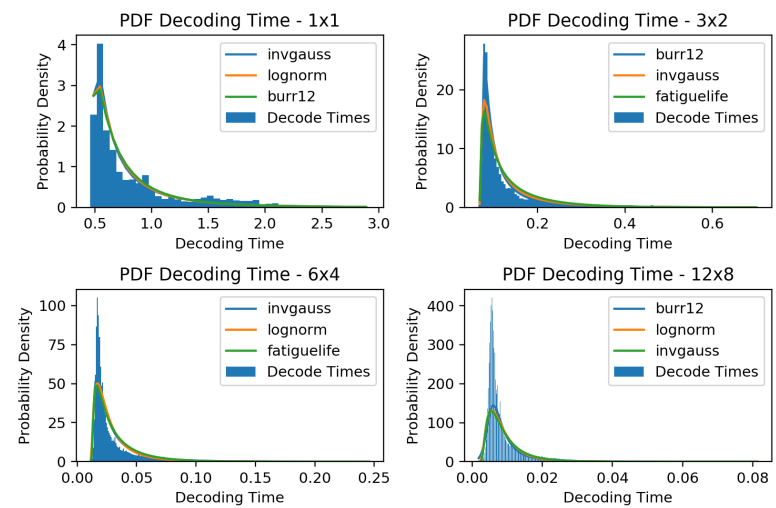

Figura 1. Histograma dos tempos de decodificação e três distribuições com menores SSE

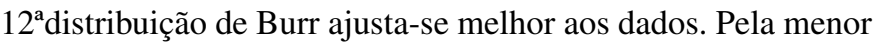
dimensão, os tiles dos particionamentos $6 \times 4$ e $12 \times 8$ possuem um tempo médio de decodificação que é $94,2 \%$ e $98,4 \%$ menores do que o vídeo sem ladrilhamento $(1 \times 1)$, respectivamente. Considerando que o usuário visualiza apenas uma fração do vídeo esférico a cada instante, e que um maior ladrilhamento resulta em crescimento apenas modesto na taxa média do vídeo codificado (ex: tiles $12 \times 8$ possui taxa média apenas 19,17\% maior do que vídeo sem ladrilhamento), é possível então esperar ganhos significativos no tempo de decodificação total e ocupação de buffer se apenas os tiles relativos ao viewport predito do usuário forem solicitados do servidor.

\section{Conclusões e Trabalhos Futuros}

Este trabalho apresentou uma caracterização estatística preliminar do tempo de decodificação de ladrilhos de segmentos de vídeos $360^{\circ}$ em diferentes dimensões e taxas de compressão. Verificou-se que a distribuição Gaussiana Inversa ajustase melhor ao ladrilhamento $3 \times 2$ e $12 \times 8$, enquanto que a $12^{\mathrm{a}}$ distribuição de Burr representa melhor o tempo de decodificação de ladrilhamentos mais refinados. Como trabalho futuro, caracterizaremos a estatística do tempo de decodificação de ladrilhos de vídeos para diferentes conteúdos de vídeo.

\section{REFERÊNCIAS}

[1] "Cisco Visual Networking Index: Global Mobile Data Traffic Forecast Update, 2017-2022 White Paper," Tech. Rep., 2019. [Online]. Available: https://www.cisco.com/c/en/us/solutions/collateral/serviceprovider/visual-networking-index-vni/white-paper-c11-738429.html

[2] C. Concolato, J. Le Feuvre, F. Denoual, F. Mazé, E. Nassor, N. Ouedraogo, and J. Taquet, "Adaptive Streaming of HEVC Tiled Videos Using MPEG-DASH,' IEEE Transactions on Circuits and Systems for Video Technology, vol. 28, no. 8, pp. 1981-1992, 2018.

[3] D. He, C. Westphal, and J. J. Garcia-Luna-Aceves, "Joint Rate and FoV adaptation in immersive video streaming," in Proc. of the Workshop on Virtual Reality and Augmented Reality Network, 2018, pp. 27-32.

[4] F. Qian, B. Han, Q. Xiao, and V. Gopalakrishnan, "Flare: Practical Viewport-Adaptive 360-Degree Video Streaming for Mobile Devices," in Proc. MobiCom, 2018. 